\title{
ATIVISMO COMO CIDADANIA NA CONTEMPORANEIDADE
}

\section{ACTIVISM AS CITIZENSHIP IN CONTEMPORARY SOCIETY}

\author{
Kátia Vanessa Tarantini Silvestri ${ }^{*}$
}

\section{RESUMO}

Cidadania é um conceito que passa por transformações semânticas ao longo dos anos. Na Grécia Antiga, cidadania era uma qualidade reservada aos homens livres e concidadãos, o que significava estarem excluídos comerciantes, artesãos, trabalhadores, mulheres, jovens e escravos. No cenário atual, cidadão é todo ser humano, visto nascermos livres e iguais em dignidade e direitos, afirma o primeiro artigo da Declaração dos direitos humanos. É nesse contexto, que podemos compreender os ativistas como atores políticos, cidadãos partícipes da vida política também de forma virtual. Os estudos de Pierre Lévy (1998; 2004), Negri e Hardt (2005a; 2005b), Agamben (2002) e Foucault (1997; 1999; 2002) são fundamentação teórica para a presente reflexão, cujo objetivo é, a partir de uma abordagem qualitativa com procedimentos bibliográficos, levantar alguns estudos de casos vinculados pela mídia acerca de ações e protestos que se aplicam à defesa do ativismo com cidadania.

Palavras-chave: Biopolítica. Consenso. Participação política. Ciberespaço.

\begin{abstract}
Citizenship is a concept that went through semantic transformations over the years. In ancient Greece, citizenship was a quality reserved to free men and citizens, which meant that merchants, artisans, workers, women, young people and slaves were excluded. In the current scenario, a citizen is every human being, since we are born free and equal in dignity and rights, says the first article of the Declaration of Human Rights. It is in this context that we can understand that activists are political actors, citizens that participate ofthe political life in the real world as well as virtually. Studies by Pierre Lévy $(1998,2004)$, Negri and Hardt (2005a; 2005b), Agamben (2002) and Foucault (1997; 1999; 2002) represent the theoretical support for this reflection, which from a qualitative approach with bibliographic procedures, aims at pointing out case studies linked by the media about actions and protests that apply to the defense of activism as a form of citizenship.
\end{abstract}

Keywords: Biopolitics. Consensus. Political participation. Cyberspace.

* Professora da Rede Estadual de ensino do Estado de São Paulo. Doutora em Linguística - UfsCar 
Não sou brasileiro, não sou estrangeiro, não sou de nenhum lugar, de lugar nenhum. Não sou de São Paulo, não sou japonês, não sou carioca, não sou português, não sou de Brasília, não sou do Brasil, nenhuma pátria me pariu.

Eu não sou nem daqui, eu não sou nem dali”

Nenhum Lugar - Titãs

\section{Breve semântica do termo cidadão}

Os direitos humanos transformam o súdito em cidadão e, o que aqui carece de explicitação é justamente a noção de cidadão. Para que haja cidadãos faz-se necessário uma nação. Para que haja uma nação são necessários cidadãos. Nação deriva etimologicamente de nascere. A nação finda um círculo, por assim dizer, inaugurado com o nascimento de indivíduos. Com efeito, tem cidadania, é cidadão, aquele que traz marcado uma combinação, solo e sangue: Ius soli e ius sanguinis, respectivamente, nascimento em determinado solo (país), e nascimento desde genitores cidadãos. Em tal lógica ser cidadão é ter nascido em determinado lugar desde pais ali nascidos também - é uma relação de filiação. "Isso significa que o nascimento - isto é, a vida nua natural como tal - torna-se aqui pela primeira vez (...) o portador imediato da soberania" (AGAMBEN, 2002, p. 135). Veem-se dois movimentos interligados, a declaração e a soberania nacional - fascismo e nazismo. Estes movimentos fazem da vida nua o locus (lugar) de toda decisão soberana, a saber, fazer viver ou deixar morrer. Vale ainda dizer que o primeiro registro de vida nua enquanto sujeito político detentor de direitos humanos emerge com o habeas corpus, "deverás ter um corpo para mostrar" (AGAMBEN, 2002, p. 130). Ou seja, é corpus a vida nua, tanto sua sujeição quanto sua liberdade, deverá ter seu corpo - liberdade - para mostrá-lo - sujeição.

É no engendramento do direito romano que se inicia o sujeito político enquanto vida nua e, no ideal de direitos humanos, esta vida torna-se, por excelência o que define genérica e universalmente cidadão.

As definições não são unilaterais apesar de alguns discursos, às vezes, quererem monologizar como nos casos do autoritarismo e do totalitarismo.
Noções como globalização e cidadania têm mais de uma face e, pode ocorrer, como veremos com os estudos acerca da biopolítica, ser uma dessas faces a da exclusão, segregação e consenso.

Portanto, o objetivo geral do artigo é demonstrar a ambivalência do discurso político no âmbito do conceito de cidadania. Por um lado, veremos as construções de imaginários coletivos cativos à lógica dominante que aqui adotamos como a noção de império. Por outro, veremos como ações individuais e protestos podem ser uma autêntica noção de responsabilidade, de consciência política e cidadania. De forma mais especifica, objetiva-se: 1) Defender o sujeito ativista como um exemplo pontual de agir cidadão, respondente e responsável, sujeito singular, atuando em sua sociedade de diferentes formas em busca de relações mais democráticas e humanas. 2) Defender o aparato tecnológico como ferramenta crucial na criação e ampliação de espaços democráticos quanto na comunicação e colaboração entre pessoas.

Para tanto, este artigo insere-se no paradigma da pesquisa qualitativa. Isso significa dizer que, assim como afirma Kramer (2003), faz parte deste tipo de pesquisa lidar com as subjetividades e/ou perspectivas das pessoas envolvidas, possuir como dinâmica a reflexão singular, admitir que as discussões apresentadas fazem parte do processo investigativo e, também, do contexto em que foi possível a realização do estudo, além de admitir a própria influência da pesquisa sobre a situação selecionada para estudo.

Metodologicamente, não podemos, conforme Bakhtin (2006a), perguntar à cultura, por exemplo, e ela nos responder; precisamos colocar as questões e organizar, observar e interpretar as respostas. Estudar o ser humano é encontrar signos por todos os lados, a tarefa do investigador nas ciências humanas e sociais é interpretar seu significado.

\section{A biopolítica nas entranhas da cidadania}

Foucault em Nascimento da biopolítica diz: "entendo "biopolítica" a maneira pela qual se tentou, desde o século XVIII, racionalizar os problemas propostos à prática governamental, pelos fenômenos próprios a um conjunto de seres vivos constituídos em população: saúde, higiene, natalidade, raças..." (FOUCAULT, 1997, p. 89). Em outras palavras, a 
declaração dos direitos humanos inaugura a biopolítica. Mas podemos indagar: quem é o sujeito desses direitos? A quem tais direitos dirigem-se? A biopolítica de comando é engendrada por um discurso constante: o bem da população. Entretanto, o bem é também um ponto de vista, uma construção lógica, um discurso habilitado ao dizer.

O governo da população - sendo esta um princípio de enriquecimento aos olhos dos mercantilistas, precisava viver para consumir e, para isto, fora necessário entre outras coisas uma política da saúde fora implantando várias técnicas de administração da população, como sensos, carteiras de saúde etc. De tais atividades muito bem intencionadas - preservar a vida é uma potencialização do ser - emerge o que Foucault define como o Estado de população, isto é, um saber político cujo eixo nevrálgico é a população, sua saúde, sua capacidade cada vez mais elevada de hereditariedade sadia. Neste exercício político, a polícia vai cada vez mais se tornando um órgão com uma especificidade em crescimento constante: promover mudança de atitude, o vigiar, controlar e exigir uma postura cada vez mais adequada à preservação da espécie. Tudo o que for considerado, pelas descobertas científicas e interesses políticos, como um mal à espécie, deve ser readaptado, reconstituído, silenciado e, em último caso, eliminado. Ela, a polícia, torna-se então a política sanitária por excelência, o órgão mediante o qual devemos dar conta de nossas atitudes, responder cadastros, afiliar-se à entidades, comunidades, ter previdência social etc.

É por meio dessa atividade policial que as práticas biopolíticas exercem-se em nas sociedades. Todavia, a pergunta é: quais são as práticas subterrâneas exercidas, quais as relações efetivadas, quais mecanismos são utilizados no engendramento da biopolítica? As práticas biopolíticas são várias.

O nascimento biopolítico está inteiramente associado à saúde pública, ou seja, àquilo que Foucault em Segurança, território e população constata como Medezinische Polizei, isto é, medicina social ou ainda higiene pública, desenvolvida desde a segunda metade do século XVIII. A polícia sanitária "tende a tratar a "população" como um conjunto de seres vivos e coexistentes, que apresentam traços biológicos e patológicos particulares, e que, por conseguinte, dizem respeito a técnicas e saberes específicos" (FOUCAULT, 1997, p. 86). Nesse contexto, de eu- genética - ciência da hereditariedade - um livro, denominado Estado e Saúde circulou entre a sociedade fazendo mérito à política nacioanal-socilista. Diz um trecho da introdução: "a revolução nacional-socialista, deseja fazer apelo às forças que tendem à exclusão dos fatores de degeneração biológica e à manutenção da saúde hereditária do povo. Ela almeja, portanto, fortificar a saúde do conjunto do povo e eliminar as influências que prejudiquem o desenvolvimento biológico da nação" (AGAMBEN, 2002, p. 154). Depois disso, muitos decretos surgiram. Entre eles, por exemplo, não podia casar dois indivíduos se, um deles, estivesse sob tutela médica, se tivesse doença mental ou hereditária. Eles não eram proibidos de ter filhos, eram, antes, proibidos de se casarem! Durante o nazismo - biopolítica - o Führer recebia listas com o nome de todos os doentes, especialmente os que tivessem doenças renais e cardíacas. A família desses indivíduos não conseguia mais levar uma vida pública e, ao indivíduo, poderia ser negada a reprodução. É nesses decretos, projetos, panfletos e desenvolvimentos científicos que a biopolítica de comando fora ganhando forma cada vez mais delineada.

Outro exemplo de nascedouro biopolítico foram panfletos a favor da eutanásia. $\mathrm{O}$ panfleto em questão, elaborado por Karl Binding (médico) e Alfred Hoche (jurista), atribuiu à atividade biopolítica uma dimensão jurídica ao afirmar que o estado de alguns pacientes, em certas situações hospitalares, era inaceitável. Dizia a proposta:

Esses homens não possuem nem a vontade de viver nem a de morrer. Por um lado, não existe nenhuma constatável anuência à morte, por outro, a sua morte não se choca contra a vontade de viver, que deva ser superada. Sua vida é absolutamente sem objetivo, mas eles a sentem como intolerável. (AGAMBEN, 2002, p. 145).

A vida sem valor é a vida que juridicamente falando não tem mais valor, de forma, que pode ser morta sem que se cometa homicídio. Todavia, o bem intencionado panfleto sobre a eutanásia intensifica a vida enquanto zoe novamente ela é o objeto de uma decisão soberana. A boa morte, significado de eutanásia, compreendida a partir da ideia de uma vida esvaziada/desvalorizada, possibilita uma convergência entre o fazer viver e o matar. Com efeito, a biologia perde o poder de determinar o que é vivo e o que 
é morto. Eis que a política ocupa o espaço deixado pela biologia.

Mesmo a biologia dizendo que a vida não paira mais sobre um determinado corpo, este pode ser mantido "vivo" por anos conforme a vontade da "justiça". Vida e morte são conceitos da política. Essa problemática de manter "vivo" acontece muito nos casos de comas. Por séculos a morte fora identificada pelo cessar de batimentos cardíacos e a parada de respiração. Porém, emerge um estado de coma cunhado por dois neurofisiólogos franceses, Mollaret e Goulon, chamado além-coma. Estes médicos estabeleceram essa nova situação a partir das técnicas inventadas de reanimação.

A parada dos batimentos cardíacos e da respiração, como critério de morte, fora substituído pela parada cerebral em 1968 por cientistas da universidade de Havard. Esse novo critério só considera morto o indivíduo que tivesse o cérebro inteiro parado, isto é, tanto o neocórtex quanto o brainsten, mesmo que pelas técnicas de reanimação continuasse respirando, por exemplo. Disso emerge, como coloca Agamben, os néomorts (novos mortos), espectros de corpos, pois "numa sala de reanimação, a qual cadáveres nem sempre o são, visto ser possível mantê-los com características de vida, seriam quentes, pulsantes e urinantes" (GAYLÏN apud AGAMBEN, 2002, p. 171).

Nota-se que os parâmetros de morte andam junto com o desenvolvimento cientifico. Exemplo é que a cada nova técnica e novos aparelhos, novos estados de coma são descobertos, como o além-coma. Desse resultado, desenvolvem-se outras novas técnicas de transplantes de órgãos e assim em diante fomentando uma circularidade entre consumo/tecnologia/definição do que está vivo e do que está morto.

Outra prática biopolítica reside ainda numa atividade muito difundida entre os experimentos científicos, as cobaias humanas. Estes são em tese, os que de alguma forma estão "excluídos". Segundo Agamben, as cobaias humanas são os motores da biopolítica. Os ditos delinquentes, capturados, refugiados, portadores de alguma doença física ou mental eram todos utilizados - principalmente nos campos de concentração - em experimentos nos quais animais não serviam. Centenas de mortes justificaram as pesquisas em nome da vida. Há aqui uma crucial questão bioética, pois testes com vacinas em prisioneiros de guerra, soldados e doentes foram executadas com o álibi de ser em nome da vida de outros, do progresso científico em nome da evolução da espécie.

A declaração dos direitos humanos, a eugenética, os decretos da polícia sanitária, as cobaias humanas, as técnicas de reanimação são exemplares da prática biopolítica de comando. Nela, o que sempre esteve e está em jogo é o fato de ser vivente. "A política é agora literalmente a decisão do impolítico (isto é, a vida nua)" (AGAMBEN, 2002, p. 181).

Negri e Hardt nos lembram de que a sociedade globalizada, a lógica de comando biopolítica que eles definem por império e sua inversão que chamam de contra império foi a resposta aos pedidos de uma multidão de sujeitos.

Foucault enfatiza que a produção biopolítica de comando sustentada no biopoder - o poder sobre o bios, bipoder - encontra em seu âmago sua derrocada. O biopoder, esse poder sobre a vida, produz vida. Duas questões são destacadas por Foucault: primeiramente o poder se exerce, ele não é um fenômeno maciço e igualitário. "O poder (...) circula (...), como uma coisa que só funciona em cadeia. $\mathrm{O}$ poder funciona. $\mathrm{O}$ poder se exerce em rede e, nessa rede, não só os indivíduos circulam, mas estão sempre em oposição de ser submetidos a esse poder e também de exercê-lo" (FOUCAULT, 2002, p. 35). A relação está posta.

Relação de enfrentamento luta e, portanto, poder; de forma que não existe sujeito neutro, passivo e totalmente alienado. "Somos forçosamente adversários de alguém" (FOUCAULT, 2002, p. 59). Mais uma mudança semântica para cidadão? Segundo Cocco e Corsani citados por Cocco e Hopstein (2002, p. 13) ser cidadão é ser um guerreador, um soldado; "quem não é soldado não pode mais ser um cidadão". Nesse sentido de luta, de responder de seu lugar único e intransferível, assumindo nossa singularidade incambiável é que poderemos olhar para o ativismo, os protestos e as manifestações como uma forma de ação, no sentido de Arendt, (2009, 335): "atividade pela qual ocorre a relação entre homens; efetivamente, é a experiência política. Especificamente humana, a ação tem condição a pluralidade de atos e palavras". 


\section{A Globalização como ausência de fronteiras: império e contra império}

Globalização, para Negri e Hardt (2005a), significa ausência de fronteiras, desterritorialização e territorialização, um não lugar, um espaço sempre aberto, inclusivo, rede e todo. Não obstante, não tem parentesco o termo império e o termo imperialismo. Longe de ser um recurso linguístico, império significa globalização. E globalização é compreendida nesse contexto como uma ordem global de produção e de cultura. Por isso, os autores de Império dizem de uma nova supremacia no exato sentido da transformação da soberania em globalização.

O espaço estriado da modernidade construiu lugares que estavam continuamente ocupados e fundamentados num jogo dialético com seu exterior. Constratando com isso, o espaço da soberania imperial é liso. Pode parecer livre das divisões binárias ou dos estriamentos das fronteiras modernas, mas na realidade é cruzado por tantas falhas que só na aparência é contínuo e uniforme. Nesse sentido, a crise da modernidade, definida com contornos claros, cede à vez a uma onicrise no mundo imperial. No espaço liso do império, não há lugar de poder - ele está ao mesmo tempo em todos os lugares e em lugar nenhum. O império é uma ou-topia, ou de fato, um não lugar (NEGRI; HARDT, 2005a, p. 210).

Lugar e não lugar são noções que podem ser compreendidas tanto pelas relações que estabelecemos ao estarmos num determinado local, quanto pelo aumento de lugares físicos. Uma pessoa que caminha pode ser vista como um não lugar. Ao andar por ruas de uma cidade esta pessoa relacionase tanto com o espaço físico quanto com outras pessoas. Tais relações estão completamente fora do controle direto da lógica imperial. Quando a identidade está fortemente marcada, pode-se compreender como um exemplo de lugar: um homem vestido de branco associado imediatamente à profissão médico.

Define-se, portanto, um lugar e um não lugar principalmente pelas relações que os indivíduos estabelecem: "um aeroporto, por exemplo, não tem o mesmo status na visão do passageiro que por ele passa e na visão de quem nele trabalha todos os dias" (AUGÉ, 1997, p. 169). Um não lugar se expressa ainda na fórmula: "espaços nos quais se coexiste ou se coabita sem viver junto, nos quais o status de consumidor ou de passageiro solitário passa por uma relação contratual com a sociedade" (AUGÉ, 1997, p. 169-70).

Alguns exemplos de não lugares são aeroportos, internet, centros de compras entre outros. São espaços de locomoção, comunicação e consumo. São as relações estabelecidas nesses espaços que darão a eles o atributo de lugar ou não lugar.

Essa possibilidade levada ao extremo de um espaço ser ou não ser um lugar, e a proliferação de espaços de consumo, comunicação e circulação caracterizam também a pós-modernidade em face à modernidade. Ou seja, caracteriza o império: um não lugar porque exposto por toda parte e, mais substancialmente, porque em potência um espaço possível tanto de identificação ou não, um espaço aberto, por isso u-tópico nas duas perspectivas semânticas tanto um espaço que não se define geograficamente porque é o mundo todo, quanto um espaço no qual depende das relações que os indivíduos mantenham para que tenha determinado significado, para que ganhe determinado status. Um não lugar porque em potência todos os lugares - espaços de identificações - possíveis.

Negri e Hardt (2005a) definem a noção de império mediante três componentes: ausência de fronteiras; suspensão da História e criação de subjetividades.

O poder exercido pela lógica imperial não reconhece nenhum tipo de fronteira, pois o império engloba tudo e, por essa razão, coloca-se como um não lugar. Ao suspender a História cria o imaginário de que tudo sempre foi assim. Uma noção de eternidade é estabelecida. Paradoxalmente, são os inúmeros acontecimentos e a velocidade ímpar de circulação de informação que faz com que a História parece impensável. Tudo se passa como se as coisas existem conforme se apresentam. Um agora que se perpetua é a impressão causada. Por essa razão, o império apresenta-se como um regime sem fronteiras temporais. E como terceiro elemento, a ordem imperial não só administra um território com sua população, mas também cria o próprio mundo que habita, cria lugares, relações, subjetividades. O objeto do governo imperial é a vida social, "produção da própria vida social na qual o econômico, o político e o cultural cada vez mais se sobrepõem e se completam" (NEGRI; HARDT, 2005a, p. 13). 
Nascido não por vontade própria, mas reivindicado, o império mantém-se pela vitalidade do organismo social: a população. "O Império não nasce por vontade própria; é convocado a nascer e constituído com base em sua capacidade de resolver conflitos" (NEGRI; HARDT, 2005a, p. 33).

São as crises da modernidade que trazem à vida o regime imperial. A queda dos estados nação é o ventre que anima as lutas de classe e, em busca de liberdade, massas indignadas forjam relações que implodem tanto o colonialismo quanto o imperialismo.

Em nossa época, esse desejo posto em movimento pela multidão foi atendido (de forma estranha e perversa, mas apesar disso real) pela construção do Império. Pode-se dizer até que a construção do Império e de suas redes globais é uma resposta às diversas lutas contra as modernas máquinas de poder, e especialmente à luta de classes, ditada pelo desejo de libertação da multidão. A multidão exigiu o nascimento do Império. (NEGRI; HARDT, 2005a, p. 62).

Na modernidade, a contra-História foi um discurso polivalente, descortinando os discursos silenciados e contanto uma outra história; a história de reivindicação, de luta por direitos e emancipação.

Entendido como uma globalização sem fronteiras espaciais e temporais, o império abrange desde o fator econômico à produção de subjetividades. $\mathrm{O}$ império cria identidades, cria consumidores; são estes que doam sangue às veias da soberania imperial. Corroboram as palavras: "para a sociedade capitalista, a biopolítica é o que mais importa, o biológico, o somático, o físico" (NEGRI; HARDT, 2005a, p. 46). Essa foi a resposta, um pouco perversa observam Negri e Hardt, da luta das multidões. Todavia,

Apesar de reconhecer tudo isso, insistimos em afirmar que a construção do Império é um passo à frente, no sentido de deixar para trás qualquer nostalgia de estruturas de poder que o precederam e recusar qualquer estratégia política que implique a volta ao velho arranjo, como, por exemplo, tentar ressuscitar o Estado-nação em busca de proteção contra o capitalismo global. (NEGRI; HARDT, 2005a, p. 62).

Algumas perguntas se fazem cruciais. Como ultrapassar o regime imperial se ele abarca tudo? Por que, apesar de ser um pedido às avessas, o império ainda é uma forma de governo mais aceitável que as antecessoras?

Fundamentados na perspectiva de uma política realista, os autores de Império afirmam que esse ir além não é passar para um outro lado, mas forjar o contra império mediante o que dispomos como ferramentas de insurreição. Não obstante, a lógica imperial pode ser compreendia como "melhor" em relação a outros regimes político-econômicos porque nela há exaustivamente a presença do biopoder - o poder constituinte.

O Império cria um potencial maior de revolução do que os regimes modernos de poder, porque nos apresenta, juntamente com a máquina de comando, uma alternativa: o conjunto de todos os explorados e subjugados, uma multidão que se opõe diretamente ao Império, sem mediação (NEGRI; HARDT, 2005a, p. 417-8).

Negri e Hardt estabelecem três ferramentas que estruturam a lógica imperial. São elas: a bomba, o capital e a linguagem. Entendamos por linguagem a produção linguística. Já por bomba, o poder de morte. Por fim, por capital, o poder financeiro.

Vimos que o comando imperial, cuja estruturação é piramidal, governa todo o mundo civilizado mediante o controle de forças, mantendo um equilíbrio próprio à lógica do poder. A ferramenta bomba, esse arsenal de armas nucleares que estão centralizadas no cume da pirâmide - Estados Unidos - desempenha a função de manter as coisas em seus lugares pré-estabelecidos pela lógica de comando.

Mais precisamente, o poder sobre a vida é controlado pela ferramenta bomba. O medo do diferente, o medo do passar dos dias, uma insegurança e diferentes discursos terroristas pairam no ar como uma ameaça constate a vida. Eis eu todas as guerras são reduzidas em guerras civis, internas e limitadas, sugerindo um estado de guerra todos contra todos, raciocínio típico da filosofia hobbesiana. A guerra torna-se questão administrativa e policial e uma grande maioria de países perdem o poder de comando, no sentido de fazer guerra externa, em face da tecnologia nuclear. Eis que essa maquinaria de morte tenta controlar desejos subversivos, povos reunidos, multidões ativas.

De nenhum outro ponto de vista a passagem da modernidade para a pós-modernidade, e da 
soberania para o Império é mais evidente do que do ponto de vista da bomba. O Império é definido aqui em última instância como o "não lugar" da vida, ou em outras palavras, como a capacidade absoluta de destruição. O Império é a forma suprema de biopoder na medida em que é a inversão absoluta do poder da vida (NEGRI; HARDT, 2005a, p. 367).

Face ao instrumental bomba o império tornase uma tanatopolítica. “... Existe uma linha em que a decisão sobre a vida torna-se decisão sobre a morte, e a biopolítica pode deste modo converter-se em tanatopolítica" (AGAMBEN, 2002, p. 128).

A segunda ferramenta é o capital - o dinheiro - como as moedas fortes, o poder financeiro subjugando as demais moedas. Há, portanto, um controle mediante o poder de consumo, restringindo e limitando as ações de milhares de pessoas em busca de uma vida mais igualitária.

Um exemplo é o paradoxo do ator político. Existe um imaginário criado pelo discurso do consenso de que todos nós somos agentes políticos, partícipes, e que, portanto, estamos em movimento, em ação. Mas basta querermos reivindicar algo que essa participação se torna um caminhar dificultado por muitas burocracias e intransigências. É o controle financeiro, a tecnocracia, que visa impedir o agir efetivamente. Enquanto estiver no imaginário coletivo o império permite, incentiva; ao se passar ao plano da prática, a lógica do império faz de tudo para criar muros intransponíveis.

Enfim, a produção linguística, comunicativa. O controle do imaginário, das subjetividades e da cultura são meios fortíssimos do controle imperial. Por meio da produção linguística o império dissemina seu comando sobre a população. Todavia, o contra império pode ser forjado desde outro uso de algumas das ferramentas que dispomos. Essa construção é fomentada pelo próprio sistema, pelas possibilidades que o próprio império permite: política realista.

Como salienta Negri, o império não é liso nem plano, basta notar as contradições em seu âmago. Tais contradições da soberania imperial emergem quando mesmo num mundo globalizado, sob a ameaça das armas nucleares, sob o controle dos corpos autogovernantes, sob o medo que se dissemina pela comunicação, experienciamos corpos dispostos a se matarem, corpos camicases.
Este poder absoluto, porém, é radicalmente discutido por práticas tais como ações suicidas - do protesto dos bonzos que ateiam fogo em si mesmos no Vietnã ao terrorista suicida que se faz explodir. Quando a própria vida é negada no esforço de contestação da soberania imperial, o poder de vida e de morte que o soberano exerce resulta ineficaz. As armas absolutas contra os corpos são neutralizadas pela negação absoluta e voluntária do corpo. (NEGRI, 2003, p. 79).

Porém, as ideologias estão em embate. Apesar de controles que se querem intransponíveis, a vontade, a força da paixão humana, o desejo de insurreição colocam em xeque, por exemplo, o controle da bomba. Uma fenda se abre sobre o que parece uma calma maré. De dentro da estrutura uma implosão se dá. Mesmo o controle financeiro é invertido, desestabilizado pelo trabalho imaterial, pelo voluntariado, pelas trocas e cooperações em diversos níveis que gradativamente diminuem a exclusão.

No âmbito do controle linguagem a situação é mais visível ainda. Para os autores de Império a regulamentação desde a produção linguística "se dissolve no éter” (NEGRI; HARDT, 2005a, p. 368). A linguagem, a construção sígnica, não comporta "qualquer controle absoluto ou unilateral" (NEGRI, 2003, p. 81). Nunca fora tão exigido da multidão criatividade, nunca o trabalho fora tão intelectual, e modo que se pode dizer de um General Intellect, uma intelectualidade coletiva - uma inteligência coletiva. Nesse sentido, a linguagem tornou-se ela mesma força produtiva. Ela é a ferramenta mais crucial na construção do contra império. E isso porque a linguagem não está subordinada à soberania imperial, ela é um não lugar por excelência; não há como dominar a produção sígnica de maneira unilateral. O sentido é fruto da relação, é fruto da interlocução, de modo que estamos sempre criando contrapalavra1. "A significação é efeito da interação

\footnotetext{
${ }^{1}$ Sempre criando contrapalavra, pois mesmo em silêncio, mesmo escutando, mesmo discordando ou concordando estamos necessariamente vinculando sentido à enunciação, estamos sempre gerando sentido. Para entender o que o outro me diz, para dialogar, para pensar, para simplesmente ser ouvinte gero uma contrapalavra, uma réplica, um raciocínio interior, uma fala interior que me permite ser sujeito falante e participar de uma comunidade linguística. Minha réplica, minha contrapalavra é o movimento, a existência da subjetividade. Jamais sou um ser mudo - isso é a morte. Sou um ser no qual o outro - o outro fictício - está sempre lá, presente, murmurando, de forma que mesmo sozinho nunca estou silenciado, nunca estou mudo. Há sempre um mundo significativo preenchendo meu ser, possibilitando minha existência. Estou sempre interagindo - replicando - seja comigo e o outro
} 
entre locutor e receptor" (BAKHTIN, 2006b, p. 132) e, não obstante, "o signo não pode ser separado da situação social sem ver alterada sua natureza semiótica" (BAKHTIN, 2006b, p. 62).

Disso resulta que a soberania imperial não tem como fiscalizar completamente a produção comunicativa, ela é em si subversiva e, é por isso, que o império investe quase todas as suas cartadas no controle linguístico. O combate a ser travado é o de uma ação linguística tanto porque "o signo é a arena na qual se dá a luta de classes" (BAKHTIN, 2006b, p. 46), quanto por uma razão comunicativa, um agir comunicativo cada vez mais possível mediante a própria ausência de fronteiras do império, por sua fomentação de espaços cada vez mais descentralizados. A (des) construção da maquinaria imperial é tanto linguística quanto alicerçada no trabalho imaterial.

Todavia, ocorre o que Negri e Hardt chamam de inimigo equivocado. Quando se pensa e age de forma binária, por exemplo, o discurso da política da localidade versus a globalização, as pessoas se equivocam a respeito de ambas. O que a política da localidade não percebe é que o império não se opõe nem a produção de identidade local nem à reterritorialização, antes, é interessante para a maquinaria imperial que existam essas identidades locais resistindo à globalização. As identidades locais que são igualmente produzidas pelos fluxos globais são, nesse sentido, uma barreira à construção do contra império, ou seja, a estratégia de resistência local identifica erroneamente o inimigo e, portanto, o mascara. (...) Mais importante, essa estratégia de defesa do local é danosa porque obscurece e até nega as alternativas reais e os potenciais de libertação que existem dentro do Império (NEGRI; HARDT, 2005a, p. 64-5).

A construção de uma cultura híbrida não se limita ao projeto de identidades locais. As raízes, não são nesse caso a forma mais eficaz de potencializar a população. Antes, elas enfraquecem tais possibilidades de emancipação. Todavia, não está sendo dito que as identidades locais devem ser rejeitadas, mas que o raciocínio dicotômico não é um lugar seguro para superar a maquinaria imperial.

A localidade é contraposta à globalização e, esta, definida como uma homogeneização cultural.

fictício - cultura, valores, crenças - seja com meu interlocutor - um sujeito falante, uma leitura, uma imagem.
Conforme Silvestri (2006, 130) “essa política da localidade oculta de fato o inimigo e acaba por cercear a população entre fronteiras, limites, enfraquecendo o poder constituinte da multidão". Não obstante, o discurso da localidade se diz natural e livre, opondo-se e resistindo aos fluxos globais do império quando, "em muitos casos o que se apresenta como identidades locais não é nem autônomo e autodeterminante, mas na verdade, alimenta-se do desenvolvimento da máquina capitalista imperial e a sustenta" (NEGRI; HARDT, 2005a, p. 64). Uma forma de pensar além do discurso binário e fundado na identidade como coesa e fixa é uma saída que se encontra nas relações estabelecidas no ciberespaço.

\section{O ciberespaço}

Seguindo os passos de Pierre Lévy (1998; 2004), o aparato tecnológico é uma defesa crucial para potencializarmos o alcance de nossas comunicações, instaurando assim novas relações, isto é, relações participativas. Por isso, defende-se a reelaboração de espaços de diálogo, de comunicação, ou seja, de criação de democracia. Pode-se indagar a razão pela qual esses espaços precisam ser reelaborados e a resposta é curta e grossa: tais espaços precisam ser arquitetados sempre que tenderem para uma estrutura monumental, sempre que ídolos sejam erguidos, sempre que a democracia seja reduzida ao discurso binário, sempre que imaginários coletivos sejam impostos.

$\mathrm{Na}$ busca pela democracia participativa as tentativas de monologia e absolutismo têm de ser abolidas se quisermos compreender por democracia, "uma política da multitudo" (NEGRI, 1993, p. 24. Um evento semântico para a noção de democracia se faz imprescindível:

Através de seus atos, seu comportamento, suas palavras, cada pessoa que participa de uma situação estabiliza ou reorienta a representação que dela fazem os outros protagonistas. Sob este aspecto, ação e comunicação são quase sinônimos. (LÉVY, 2004, p. 21).

A significação surge de cada ato do individuo. Os sentidos afetam a todos em seu contexto emergente, por isso tudo o que fazemos se torna, numa formula aristotélica, ação política, pois 
animais racionais, animais políticos. Por isso Lévy critica a democracia representativa ao subjugar a comunicação a um nível limitadíssimo. Diz ele que "a democracia só progredirá explorando da melhor forma as ferramentas de comunicação contemporânea" (LÉVY, 1998, p. 62).

A democracia representativa surge para resolver o problema de coordenação, visto tanto o número de cidadãos quanto a dispersão dos cidadãos pelos territórios de uma mesma nação. Em nossa época o ciberespaço pode ser uma forma razoável de desenvolvimento da democracia representativa possibilitando a invenção de uma democracia direta (participativa), tendo por mediador somente uma ferramenta eletrônica. É claro que ninguém ao sugerir uma democracia mais participativa usando da noção de direta proponha um cidadão total no sentido de restringir toda aspiração e atividade humana à política, um viver para a política. Se por democracia direta se entende literalmente a participação de todos os cidadãos em todas as decisões a eles pertinentes, a proposta é insensata. (...) Não creio existir alguém que invocando a democracia direta pretenda fazer tal solicitação (BOBBIO, 1997, p. 43). O ciberespaço, a internet, fomenta efusivamente a participação mais intimista, mais próxima, mais direta. Bobbio (1997), mesmo cuidadoso quando o assunto é a democracia reconhece que:

Quanto ao referendum, que é o único instituto de democracia direta de concreta aplicabilidade e de efetiva aplicação na maior parte dos estados de democracia avançada, trata-se de um expediente extraordinário para circunstâncias extraordinárias. Ninguém pode imaginar um estado capaz de ser governado através do contínuo apelo ao povo (...). Salvo na hipótese, por ora de ficção científica, de que cada cidadão possa transmitir seu voto a um cérebro eletrônico sem sair de casa e apenas apertar um botão (BOBBIO, 1997, p. 53-4).

Todavia, como propõe Lévy, a internet é a ferramenta da qual dispomos para criamos um espaço correspondente à nossa sociedade complexa. "Ter como mediador fundamental um cérebro eletrônico já não é ficção científica, em pleno século XXI a democracia virtual é uma memória de futuro" (SILVESTRI, 2006, p.148). Ou como diz Bobbio: "Mas hoje a ideia de que a democracia direta se tenha tornado possível pelo uso dos computadores não é mais o fruto de uma imaginação extravagante" (BOBBIO, 1997, p. 105-6). Consenso é o nome e ideia relacionados aos de povo e de representação: consenso é a adesão e alienação, identificação com o representante. Não é por acaso que o conceito de consenso venha se identificando cada vez mais com o conceito de consumo.

Essa aproximação ao consenso nos propõe o problema de uma nova definição, quando não se tratar, sem dúvida, da superação da representação. Se a representação é um conceito de alienação das potências dos cidadãos em favor do soberano moderno, e o consenso, uma metáfora desse processo, nosso problema será, pelo contrário, o de dar forma política a expressão da multidão nesse processo, uma forma política que não seja de alienação da potência produtiva e da liberdade dos sujeitos (NEGRI; LAZZARATO, 2001, p. 148-9).

Não obstante, as relações entre pessoas e as tecnologias digitais promoveriam uma significativa melhora da política do espetáculo (do consenso) na visão de pensadores como Lévy. Pelo ciberespaço, cada um de nós teríamos potencializada nossas ações e iniciativas políticas, minimizando os paradoxos que o regime imperial nos oferece. Para Lévy, a hibridização homem-máquina não traz consigo o perigo de revoltas maquínicas, como muitas vezes podemos concluir, antes, tem usos bastante úteis.

Seu uso mais útil, em termos sociais, seria sem dúvida fornecer aos grupos humanos instrumentos para reunir suas forças mentais a fim de constituir intelectuais ou "imigrantes" coletivos. A informática comunicante se apresentaria então como a infraestrutura técnica do cérebro coletivo ou do hipercórtex de comunidades vivas. O papel da informática e das técnicas de comunicação com base digital não seria "substituir o homem", nem aproximar-se de uma hipotética "inteligência artificial", mas promover a construção de coletivos inteligentes, nos quais as potencialidades sociais e cognitivas de cada um poderão desenvolver-se e ampliar-se de maneira recíproca. (LÉVY, 1998, p. 25).

Nas palavras de Negri e Hardt, o que se busca é a construção do pós-humano, ou seja, produzir novamente o humano cuja singularidade residirá na junção entre nomadismo e barbárie. Num contexto cada vez mais acelerado de virtualidade nos tornamos 
um novo tipo de nômades assim como um novo tipo de bárbaros.

O êxodo antropológico é importante, sobretudo porque aqui é onde a face positiva, construtiva, da mutação começa a aparecer: uma mutação ontológica em marcha, a invenção concreta de um primeiro novo lugar no não lugar. (...) Ferramentas sempre funcionaram como uma espécie de mutação antropológica tanto em termos individuais como em termos de vida social coletiva. A forma contemporânea de êxodo e a nova vida bárbara exigem que ferramentas se tornem próteses criativas, libertando-nos das condições da humanidade moderna (NEGRI; HARDT, 2005a, p. 235 e 237).

A defesa ao hibridismo humano/cultural é a busca por meios de permitir à população uma realidade indubitavelmente democrática. Será ingenuidade desejar uma democracia mais prática, mais próxima da matéria bruta? Num mundo no qual as tecnologias nos permitem uma comunicação em tempo real, diálogos e afetos sem fronteiras e mediadores, usaremos a tecnologia para diminuir a tecnocracia, a burocracia e o baixo rendimento.

(...) o principal projeto arquitetônico do século XXI será imaginar, construir e organizar o espaço interativo e móvel do ciberespaço. Talvez seja possível, então, superar a sociedade do espetáculo para abordar uma era pós-mídia, na qual as técnicas de comunicação servirão para filtrar o fluxo de conhecimentos, para navegar no saber e pensar juntos, em vez de carregar consigo massas de informação. (LÉVY, 1998, p. 26).

Um novo discurso político substancialmente ontológico se desenvolve a partir de uma ética da comunicação cuja ação não é a criação de entidades fixas, territorializadas, mas de inteligentes coletivos, da intelectualidade da multidão na comunidade dos falantes, desterritorializados, móveis, conectados à rede e trabalhando juntos. Essa nova comunidade linguística se desenvolve pelo êxodo, pelo abandono de imaginários coletivos como os mitos da igualdade, de consenso e de ator político.

Uma política da diferença como uma democracia em tempo real mais participativa requer que cada um de nós esteja comprometido com um agir social. Nesse caso, a ação vale mais que a intenção. Aqui mais do que nunca a hibridização contribui de maneira determinante. Ao pensar em termos de governabilidade democrática, pode-se indagar: "como governar em situação de desterritorialização acelerada”? (LÉVY, 1998, p. 59). Segundo a proposta de Lévy é a democracia virtual, aquela possível pela a infovia, um modo mais adequado de governo. Para Lévy, o acesso à internet está desenvolvendo-se de maneira acelerada e, com ela, uma nova realidade política pode ganhar força. Essa realidade é a mudança de uma forma ainda pouco aberto-participativa a uma forma mais interativo-participativa. Conectados à internet, todos poderão com maiores facilidades discutir, opinar e decidir juntos. Mesmo parecendo para muitos uma utopia em seu sentido de pura fantasia, Lévy usa de um exemplo para defender sua hipótese, diz ele:

Os regimes autoritários tiveram dificuldades em resistir às redes telefônicas, aos satélites de televisão, ao fax, às fotocopiadoras, a todos os instrumentos que estimulam uma comunidade descentralizada, transversal e não hierarquizada. (LÉVY, 1998, p. $60)$.

De maneira semelhante, a democracia representativa pode não resistir aos internautas conectados à rede devido ao nomadismo, sujeito indeterminado, qualquer um/todos, e à desterritorialização - lugar e não lugar.

Concebido como um verdadeiro serviço público, o ciberespaço supera a comunicação molar em prol da molecular. A comunicação molar definese pelo sistema escuta estática bastante comum nas comunicações de massa, isto é, o jornal, o rádio e televisão. Toda forma de comunicação molecular, ao contrário, define-se pela interação com o contexto, pela imanência e dinamismo permitido a toda a comunidade falante, pela auto-organização e pela valorização das qualidades humanas. Essas são as capacidades singulares sendo valorizadas independente da idade, do sexo, da condição financeira, da escolaridade, da fama que autoriza o dizer.

É preciso estar claro que a inteligência coletiva nada tem a ver com massificação, é exatamente nesse ponto que o agir ético reside. Ao ser oposta à ideia de formigueiro no qual "as formigas isoladamente são estúpidas e não sabem que o que fazem se compõe aos atos individuais" (LÉVY, 1998, p. 30-1), a inteligência coletiva não é "nem maciça nem uniforme" 
(LÉVY, 1998, p. 66), antes, ela é uma sinfonia, um coral, uma polifonia. Nesse sentido, a compreensão do diálogo tanto como interação mútua e não concordância passiva, quanto um ato de responder como responsabilidade se faz imprescindível.

Compreender a enunciação de outrem significa orientar-se em relação a ela, encontrar o seu lugar adequado no contexto correspondente. A cada palavra da enunciação que estamos em processo de compreender, fazemos uma réplica. Quanto mais numerosas e substanciais forem, mais profunda e real é a nossa compreensão (BAKHTIN, 2006b, p. 131-2).

A rede, as relações que por ela são potencializadas são múltiplas e diversas. Sabemos que os discursos estão em tensão de forma que hora buscam se estabilizar em gêneros secundários como o discurso político, ético, educacional e em outros momentos são desestabilizados por discursos primários como as falas, os diálogos pessoais do cotidiano. O ciberespaço trabalha com ambos. Por isso a responsabilidade é do sujeito falante que ao participar de uma conversação seja ela virtual ou não é responsável por suas ações e palavras, não existindo álibis para nossas ações e falas, visto serem elas necessariamente escolhas. Por isso a democracia é cada vez mais entendida como a criação de espaços enunciativos, de fala, onde cada um pode e deve expressar-se. Por essa perspectiva, o ativismo que vem se fortalecendo nos últimos anos é um exemplo do agir político, da ação participativa e de uma inteligência coletiva alimentada pelos meios digitais. O que em outras palavras, podemos definir como uma cidadania digital.

\section{Cidadãos contemporâneos: o ativismo como resposta}

Proponho que pensemos o ativismo como uma atividade responsiva. A mídia denominou de ativistas de sofá os sujeitos que de dentro de suas casas, sentados à frente de seus computadores conectados à internet, participam de abaixo assinados, por exemplo, a favor de mais justiça, igualdade. Esse termo, que aparece na mídia, também como ciberativismo, nos auxilia na compreensão de atividades democráticas cujo fortalecimento advém de ações singulares que juntas formam multidões de sujeitos que respondem às ideologias oficiais de forma ativa e responsável.
Mesmo de dentro de sua casa ou trabalho pode-se agir eticamente por uma vivência estética. Por mais que haja discursos que dão ao termo um tom pejorativo vinculando à preguiça ou comodismo de não sair às ruas e se contentar em manifestar através da internet, vemos nessas ações a mesma força em confrontar as relações de poder, apesar, é claro, da segurança em estar dentro de casa que os ativistas de sofá desfrutam e dos perigos de estar nas ruas enfrentando a força policial e os tumultos que podem também gerar riscos a própria vida que os ativistas nas ruas encaram.

Esteja de corpo presente nas ruas ou sentado diante de um computador, a ação ativa e participativa acontece, isto é, responde-se reconhecendo a obrigatoriedade e não sendo indiferente. "O ato responsável é, precisamente, o ato baseado no reconhecimento desta obrigatória singularidade. (...) porque ser realmente na vida significa agir, é ser não indiferente ao todo na sua singularidade" (BAKHTIN, 2010, p. 99).

Um exemplo de não ser indiferente foi a ação em 18 de out. 2013, quando ativistas que lutam pelos direitos dos animais, invadiram o Instituto Royal, laboratório farmacêutico localizado na cidade de São Roque - SP, e resgataram quase 200 animais entre cachorros da raça Beagle e coelhos. Alguns dos ativistas estavam acorrentados ao portão do Instituto desde o dia 12 do mesmo mês como forma de protesto. A união entre os Anonymous Brasil, os Black Bloc Brasil, ativistas ligados as $O N G s$ de proteção aos animais e as várias petições onlines que as redes sociais promoveram, fizeram com que o caso ganhasse ampla divulgação envolvendo uma multidão de pessoas. Os compartilhamentos promovidos pelas redes sociais promovem uma comunicação sem fronteiras e sem limites, possibilitando que os embates ideológicos, fossem inseridos num diálogo maior.

O ex-secretário nacional de Justiça e diretor da Avaaz no Brasil Pedro Abramovay, em entrevista ao repórter Luís Guilherme Barrucho, publicada pela BBC Brasil, (10 maio. 2013. Acesso em 03 dez. 2014), diz:

(...) Ao assinar e compartilhar uma petição online, o usuário está manifestando sua vocação política entre seus amigos, o que amplia a discussão e fortalece o ambiente democrático. Além disso, a internet encurtou a distância para que os pleitos da 
população sejam atingidos. Se antigamente eram necessários intermediários, como associações ou sindicatos, hoje qualquer um pode mobilizar seus pares de forma muito mais rápida para fazer valer seus interesses. Não há dúvida de que essa nova forma de mobilização também tenha um impacto político. Ainda que nessa área os resultados nem sempre sejam positivos, como no abaixo-assinado que pedia a renúncia de Renan Calheiros da presidência do Senado, a manifestação mostrou, acima de tudo, que os brasileiros não são tolerantes com a corrupção...

Já Lévy, em entrevista ao repórter Bruno Lupion para o jornal Estado de S. Paulo (11 mar. 2013. Acesso em 03 dez. 2014), diz:

Pergunta: Qual a relevância dos abaixo-assinados online para pressionar os parlamentares?

Lévy: Eu penso que seja tão relevante como os abaixo-assinados escritos. Uma petição é uma petição. Uma petição online só é mais fácil de organizar!

Pergunta: Sendo mais fácil, o Sr. não acha que há um risco de promover o "ativismo de sofá" nesse tipo de campanha?

Lévy: Eu não sou contra o ativismo de sofá. Qualquer forma que o cidadão use para se expressar é positiva.

Os diferentes horizontes que se encontram - as assinaturas nos abaixo assinados, os cartazes que diferentes pessoas seguram pelas ruas - são exemplos da participação política a partir da alteridade, abrindo-se ao mundo conectado, globalizado e, de dentro dele, de seus limites e ocultamentos, criar relações outras. Vejamos o exemplo de Anonymous. É uma ligação não orgânica - pois situada em alguma ordem e à sua maneira - entre diferentes sujeitos. Não é o discurso da identidade local que se vê ser afirmado nessa relação, mas o da alteridade, da interligação não entre iguais promovendo as exclusões dos diferentes, mas da relação entre diferentes de forma não indiferente.

Espalhados por todo o mundo, os participantes Anonymous, por exemplo, lutam por diversas causas a favor da liberdade, igualdade e justiça e os membros desse corpo grotesco não se conhecem, necessariamente, mas se reconhecem a partir do comum, um desejo de estabelecer relações humanizadas.
Os ativistas que lutam de diferentes maneiras estão nos dizendo que o discurso de que liberdade é uma doação tem de ser rejeitado. Liberdade é uma conquista diária, que requer esforço e dedicação.

Em meio a luta pelo contra império, isto é, por relações não fundadas no sobrenome, no dinheiro e na indiferença existem formas distintas de resposta. Porém, não se pode ser sujeito e consequentemente cidadão anulando-se. Existir, diz Bakhtin (2010), é tomar uma posição e, essa consciência responsiva permite a cada indivíduo e à sociedade à liberdade da palavra, a democracia. De forma alguma isso significa tranquilidade e facilidade. Antes, a tensão e o embate se fazem necessários. Doses de violência democrática se tornam ferramentas atuais.

Violência e crueldade não é a mesma coisa. Conforme Bezerra Júnior (2006, p.44), a violência deriva da impossibilidade da crueldade. Sobre esse ponto, Sodré (2006, p. 40) diz também que a crueldade é indice de que a violência perdeu sua finalidade histórica. Não obstante, Bezerra (2006, p.44) defende ainda que é um lugar comum a afirmação que a pobreza é causa da violência. Sodré (2006, p. 35) ressalta que existe uma violência invisível, que podemos entender como a violência contra a democracia, pois se refere àquela violência frequentemente ignorada: a violencia do poder instituido; à violência dos órgãos burocráticos; à violência do Estado; à violência do serviço público. Negri e Hardt (2005b) dizem que é necessário pensar sobre a violência para que os discursos que pregam "que a violência do forte é automaticamente legitimada, e a violência do fraco, imediatamente taxada de terrorismo" (p. 55) não se tornem uníssonos. Gadea (2011), diz que se pode compreender o uso da violência como forma de estabelecer o conflito concreto até então ausente.

Seja a violência do se despir das mulheres do Femen, seja a violência das ações dos Black Block Brasil, seja a violência das palavras de Anonymous, seja a violência estética de imagens e letras de música que nos tiram do lugar do conforto o desafio é compreender as ações mesmo quando violentas, mas não cruéis como forma de transgrediência.

A cidadania digital de nosso espaço globalizado não é a àgora perfeita, mas é na tensão cotidiana de criar relações democráticas que não nos afiliamos a banalidade do mal e que não nos alienamos. A 
cidadania digital que aqui uso o exemplo dos ativistas que ampliam suas iniciativas e convidam milhares de pessoas mediante o ciberespaço é um responder. Esse responder se dá de maneiras diferentes. Um artigo, uma petição online que se assina, uma aula que se leciona, uma conversa com os amigos e parentes, um curtir postagens que geram auxílios à ONGs ou instituições, o escrever uma carta coletiva e postar nas redes sociais, um rolezinho pelos shoppings, enfim, ações.

\section{Referências}

AGAMBEN, G. Homo Sacer - o poder soberano e a vida nua - I. Belo Horizonte: UFMG, 2002.

ARENDT, H. A condição humana. Rio de Janeiro: Forense Universitária, 2009.

Eichmann em Jerusalém: um relato sobre a banalidade do mal. São Paulo: Cia das Letras, 1999.

ATIVISTAS invadem laboratório para libertar cães usados em testes. Estado de S. Paulo. 18 out. 2013. Matéria de José Maria Tomazela. Disponível em: <http://www.estadao. com.br/noticias/cidades, ativistas-invadem-laboratorio-paralibertar-caes-usados-em-testes, $1087136,0 . \mathrm{htm}>$. Acesso em 02 dez. 2014.

AUGÉ, M. Por uma antropologia dos mundos contemporâneos. Rio de Janeiro: Bertrand Brasil, 1997.

BAKHTIN, M. Metodologia das Ciências Humanas In: Estética da criação verbal. São Paulo: Martins Fontes, 2006a.

$\overline{\text { Hucitec }}$, 2006b.

Marxismo e filosofia da linguagem. São Paulo:

. Para uma filosofia do ato responsável. São Carlos:

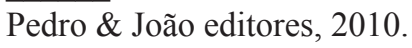

BRASIL vive boom de petições online. BBC Brasil. 10 maio. 2013. Matéria de Luís Guilherme Barrucho. Disponível em: <http://www.bbc.co.uk/portuguese/ noticias/2013/05/130509_brasil_peticoes_online_lgb. shtml>. Acesso em 03 dez. 2014.

BEZERRA. JR., B. Pobreza, agressividade e consumo: três observações sobre a violência no Brasil In: FEGHALI. J.; MENDES. C. e Lemgruber. J. (Org.). Reflexões sobre violência urbana - (in) seguranças e (des)esperanças. Rio de Janeiro: Mauad X. 2006.p. 43-60.

BOBBIO, N. O futuro da democracia - uma defesa das regras do jogo. Rio de Janeiro: Paz e Terra, 1997.

COCCO, G. ; HOPSTEIN, G. (org.). As multidões e o Império - entre globalização da guerra e universalização dos direitos. Rio de Janeiro: DP\&A, 2001.
NÃO sou contra o ativismo de sofá afirma o filósofo francês Pierre Lévy. Estado de S. Paulo. Entrevista. 11 mar. 2013. Disponível em: <http://www.estadao.com.br/noticias/ nacional,nao-sou-contra-o-ativismo-de-sofa-afirma-ofilosofo-frances-pierre-levy,1007313,0.htm? $\mathrm{p}=1>$. Acesso em 03 dez. 2014.

FOUCAULT, M. Em defesa da sociedade. São Paulo: Martins Fontes, 1999.

Microfísica do poder. Rio de Janeiro: Graal, 2002..

Resumo dos cursos do Collège de France (19701982). Rio de Janeiro: Zahar, 1997.

GADEA, C. A. A violência e as experiências coletivas de conflito. Revista Crítica de Ciências Sociais. 92. p. 75-98, 2011.

KRAMER, S. Ciências Humanas e Pesquisa: Leituras de Mikhail Bakhtin. São Paulo: Cortez, 2003.

LEMGRUBER. J. (orgs.). Reflexões sobre violência urbana. Rio de Janeiro: Mauad X. 2006. p. 33-42.

LÉVY, P. A inteligência coletiva: por uma antropologia do ciberespaço. São Paulo: Loyola,1998.

As tecnologias da inteligência - o futuro do pensamento na era da informática. Rio de Janeiro: Editora 34, 2004.

NEGRI, A. A anomalia selvagem - poder e potência em Spinoza. Rio de Janeiro: Editora 34, 1993.

DP\&A, 2003.

Cinco lições sobre Império. Rio de Janeiro:

NEGRI, A.; HARDT, M. Império. Rio de Janeiro: Record, 2005a.

Multidão - Guerra e democracia na era do império. Rio de Janeiro: Record, 2005b.

NEGRI, A. \& LAZZARATO, M. Trabalho imaterial formas de vida e produção de subjetividade. Rio de Janeiro: DP\&A, 2001.

SILVESTRI, K. V. T. Diz-sensu: e contra império e diferença desde a ação linguística. 2006. 187 f. Dissertação (Mestrado em Linguística) - Centro de Educação e Ciências Humanas- Departamento de Letras/Programa de Pós-graduação em Linguística, Universidade Federal de São Carlos, São Carlos, 2006. Disponível em: $<$ http://www. ufscar.br/ ppgl/Dissertacao\%20Katia\%20Vanessa.pdf>.

SILVESTRI, K. V. T. A carnavalização como transgrediência da multidão. 2014. 213 f. Tese (Doutorado em Linguística) - Centro de Educação e Ciências Humanas- Departamento de Letras/Programa de Pósgraduação em Linguística, Universidade Federal de São Carlos, São Carlos, 2014. Disponivel em: <http://www.ppgl. ufscar.br/novo/Defesas.php?lingua_id $=2 \&$ defesa_id $=69>$. 
SODRÉ, M. Violência, mídia e política. In: FEGHALI. J.; MENDES. C.; LEMGRUBER. J. (orgs.). Reflexões sobre violência urbana. Rio de Janeiro: Mauad X. 2006. p. 33-42.

Recebido em: 04-12-2014

Aceito em: 09-02-2015 